\title{
REAÇÃO DE CULTIVARES DE MORANGUEIRO AO OÍDIO SOB CONDIÇÕES DE CASA DE VEGETAÇÃO ${ }^{1}$
}

\author{
RAFAEL UCKER BRAHM², BERNARDO UENO ${ }^{3}$, ROBERTO PEDROSO DE OLIVEIRA ${ }^{3}$
}

\begin{abstract}
RESUMO - O objetivo deste trabalho foi avaliar a reação de dez cultivares de morangueiro ao oídio (Sphaerotheca macularis f.sp. fragariae). Plantas-matrizes foram transplantadas em bandejas de 72 células, contendo substrato autoclavado. Em seguida, bandejas com plantas de morangueiro severamente infestadas com oídio foram colocadas na casa de vegetação. Utilizou-se do delineamento experimental de blocos casualizados, com parcelas subdivididas e quatro repetições, contendo dez plantas. As parcelas foram constituídas de dez cultivares de morangueiro (Aromas, Bürkley, Camarosa, Campinas, Dover, Milsei-Tudla, Oso Grande, Santa Clara, Sweet Charlie e Vila Nova) e as subparcelas de três épocas de avaliação da severidade da doença nas três folhas mais novas totalmente expandidas $\left(8^{\mathrm{a}}, 10^{\mathrm{a}} \mathrm{e} 12^{\mathrm{a}}\right.$ semana após o transplantio das plantas-matrizes). Utilizou-se de uma escala de notas, onde $0 ; 1 ; 2$ e 3 representaram, respectivamente, $0 \%, 1-25 \%, 26-50 \%$ e $>51 \%$ de área foliar coberta com estruturas do fungo. A severidade da doença diminuiu com a proximidade do verão, devido às maiores temperaturas médias diárias. Verificou-se alta variabilidade das cultivares quanto à reação ao oídio, sendo: 'Milsei-Tudla' altamente resistente; 'Camarosa', 'Aromas', 'Oso Grande', 'Sweet Charlie' e 'Campinas' medianamente resistentes; 'Dover' pouco resistente; e 'Bürkley', 'Vila Nova' e 'Santa Clara' altamente suscetíveis.
\end{abstract}

Termos para indexação: Fragaria $\mathrm{x}$ ananassa, Sphaerotheca macularis, severidade, mudas

\section{REACTION OF STRAWBERRY CULTIVARS TO POWDERY MILDEW UNDER GREENHOUSE CONDITIONS}

ABSTRACT - The aim of this work was to evaluate the reaction of ten strawberry cultivars to powdery mildew (Sphaerotheca macularis f.sp. fragariae). Mother plants were transplanted into autoclaved substrate in trays with 72 cells. The disease inoculation was done by placing plants severely infested with powdery mildew in the greenhouse. The experimental design was a randomized block with split plot and four replications with ten plants. The cultivars tested were Aromas, Bürkley, Camarosa, Campinas, Dover, Milsei-Tudla, Oso Grande, Santa Clara, Sweet Charlie and Vila Nova. The disease severity was evaluated in the youngest 3 leaves during three periods: $8^{\text {th }}, 10^{\text {th }}$ and $12^{\text {th }}$ week after transplanting. A rating scale was used, in which $0,1,2$ and 3 represented $0 \%, 1-25 \%, 26-50 \%$, and $>51 \%$ of leaf surface covered with fungal structures, respectively. The disease severity reduced with the proximity of the summer, because of higher daily average temperature. High variability to powdery mildew resistance among the cultivars was verified. 'Milsei-Tudla' showed high resistance. 'Camarosa', 'Aromas', 'Oso Grande', 'Sweet Charlie' and 'Campinas' exhibited average resistance. 'Dover' showed little resistance and 'Bürkley', 'Vila Nova' and 'Santa Clara' were highly susceptible.

Index terms: Fragaria $\mathrm{x}$ ananassa, Sphaerotheca macularis, severity, runner plants.

\section{INTRODUÇÃO}

O morango é cultivado e apreciado nas mais variadas regiões do mundo. Produzido predominantemente em propriedades familiares, destaca-se pela alta rentabilidade por área, podendo a produção ser destinada ao mercado de frutas frescas e à industrialização (Resende et al., 1999).

A espécie cultivada, Fragaria x ananassa Duch., é um híbrido entre espécies originárias do continente americano (Fragaria virginiana x Fragaria chiloensis) (Staudt, 1962). Atualmente, algumas cultivares também incluem genes de Fragaria ovalis.

A produção mundial de morango é de 3,1 milhões de toneladas por ano e a brasileira de 40 mil toneladas, destacando-se os Estados de São Paulo, Minas Gerais e Rio Grande do Sul (Oliveira Jr. \& Manica, 2003). As principais cultivares utilizadas no Brasil provêm dos Estados Unidos, destacando-se a 'Aromas', 'Camarosa', 'Dover', 'Oso Grande' e 'Sweet Charlie', da Espanha, como a 'Milsei-Tudla', dos programas de melhoramento genético da Embrapa Clima Temperado ('Bürkley', 'Santa Clara' e 'Vila Nova') e do Instituto Agronômico - IAC ('Campinas').

Várias doenças, causadas por fungos, bactérias, vírus, viróides e micoplasmas, afetam o morangueiro (Osório \& Fortes, 2003). Nos últimos anos, com a gradual adoção do sistema de produção em cultivo protegido, sob estufa ou túnel, o oídio tornou-se uma das principais doenças da cultura (Xiao et al., 2001). Segundo esses autores, períodos curtos de molhamento foliar e alta temperatura no túnel plástico contribuem para a alta incidência de oídio em morangueiro comparado com plantios a campo. O desenvolvimento da doença é favorecido por baixa incidência luminosa, folhas sem a presença de filme de água e temperaturas entre $15^{\circ} \mathrm{Ce} 27^{\circ} \mathrm{C}$ (Mass, 1998; Fortes \& Couto, 2003). A temperatura ótima para a germinação de conídios de oídio é de $20^{\circ} \mathrm{C}$ e, para a expansão da lesão, de $25^{\circ} \mathrm{C}$ (Miller et al., 2003).

O oídio ocorre em plantios de morangueiro de todo o mundo, sendo causado pelo fungo Sphaerotheca macularis (Wallr.ex Fr.) Jacz. f.sp. fragariae Peries (Mass, 1998). Este fungo provoca danos severos nas folhas, nas flores e nos frutos, comprometendo a produtividade e a qualidade da produção (Mass, 1998).

Atualmente, as principais estratégias utilizadas no controle da doença têm sido o uso de mudas sadias, a eliminação de material vegetal com sintomas e o emprego de fungicidas durante o cultivo, com finalidade preventiva e/ou curativa (Legard et al., 1999). No entanto, uma das medidas mais importantes para o controle da doença consiste na utilização de materiais genéticos resistentes ao patógeno.

As cultivares de morangueiro apresentam diferentes níveis de resistência ao oídio (Nelson et al., 1996), não sendo descrita a reação para várias cultivares comerciais. Além disso, a interação entre os fatores ambientais e o desenvolvimento do patógeno não são completamente entendidas, sendo sugerida a existência de variantes regionais (Miller et al., 2003).

O objetivo deste trabalho foi avaliar a reação das cultivares de morangueiro Aromas, Bürkley, Camarosa, Campinas, Dover, MilseiTudla, Oso Grande, Santa Clara, Sweet Charlie e Vila Nova a S. macularis f.sp. fragariae, sob condições de casa de vegetação.

\section{MATERIALE MÉTODOS}

O experimento foi conduzido no interior de casa de vegetação de vidro adequadamente desinfestada da Embrapa Clima Temperado, em Pelotas-RS (latitude de 31 $40^{\circ} 47^{\prime \prime}$ sul, longitude de 52 $26^{\prime} 24^{\prime \prime}$ oeste e altitude de 60 metros).

No início do mês de setembro de 2003, 40 plantas-matrizes de cada cultivar, provenientes de cultura de meristemas, foram

\footnotetext{
${ }^{1}$ (Trabalho 137/2004). Recebido: 21/10/2004. Aceito para publicação: 07/07/2005. Financiado pela FAPERGS.

${ }^{2}$ Graduando de Ecologia, UCPel, Felix da Cunha, 412, CEP 96010-000, Pelotas-RS. Bolsista FAPERGS. E-mail: rafaelubrahm@bol.com.br

${ }^{3}$ Eng. Agrôn., Dr., Embrapa Clima Temperado, Caixa Postal 403, 96001-970, Pelotas-RS. Bolsista CNPq. E-mail: rpedroso@cpact.embrapa.br
} 
transplantadas em bandejas alveoladas de poliestireno de 72 células, contendo substrato autoclavado à base de terra vegetal e esterco, na proporção de 2:1. As bandejas foram dispostas em bancadas, a 1,20 m de altura. Ao redor, foram adicionadas bandejas contendo plantas de morangueiro das cultivares Santa Clara e Bürkley severamente infestadas com $S$. macularis f.sp. fragariae, buscando-se estabelecer um ambiente com alta pressão de inóculo.

O delineamento experimental utilizado foi o de blocos casualizados, com parcelas subdivididas e quatro repetições. As unidades experimentais foram constituídas por dez plantas, as parcelas por dez cultivares de morangueiro e as subparcelas por três épocas de avaliação da severidade da doença.

As cultivares de morangueiro estudadas foram Aromas, Bürkley, Camarosa, Campinas, Dover, Milsei-Tudla, Oso Grande, Santa Clara, Sweet Charlie e Vila Nova.

As épocas de avaliação da severidade da doença foram na $8^{\text {a }}$, $10^{\mathrm{a}}$ e $12^{\mathrm{a}}$ semana após o transplantio das plantas-matrizes. Utilizou-se de uma escala de notas, feita especificamente para avaliar o presente trabalho, onde $0 ; 1 ; 2$ e 3 representaram, respectivamente, $0 \%, 1-25 \%$, $26-50 \%$ e $>51 \%$ de área foliar coberta com estruturas do fungo. As três folhas mais novas totalmente expandidas de cada planta foram avaliadas, resultando em um índice de doença (ID) de 0 a 3 . O índice de doença foi a média das notas atribuídas para as folhas de cada planta avaliada.

Durante o experimento, a irrigação foi efetuada diariamente e de forma manual, de acordo com a necessidade das plantas. Não foram realizados controle fitossanitário e adubação complementar das plantas. Procurou-se manter a temperatura da casa de vegetação entre $18^{\circ} \mathrm{C}$ e 25 ${ }^{\circ} \mathrm{C}$, utilizando refrigeração e sistema de aquecimento. O monitoramento das temperaturas médias máxima e mínima diárias foi realizado por meio de termoigrômetro.

Para a análise estatística, os IDs foram transformados para log $(\mathrm{x}+1)$ e, em seguida, foram submetidos à análise de variância, sendo feita a comparação das médias pelo teste de Duncan $(p \leq 0,05)$, utilizando o programa SANEST.

\section{RESULTADOS E DISCUSSÃO}

O principal sintoma visual observado nas cultivares estudadas foi o desenvolvimento de um micélio de coloração esbranquiçada de $S$. macularis f.sp. fragariae na superfície das folhas, sendo a área coberta com as estruturas do fungo diretamente proporcional ao grau de suscetibilidade da cultivar. As folhas das cultivares mais suscetíveis também apresentaram sintomas de murcha, enrolamento das bordas em direção à nervura central, seca e, conseqüente, queda.

TABELA 1 - Índice médio de doença (ID) e reação de resistência de dez cultivares de morangueiro (Fragaria $\mathrm{x}$ ananassa Duch.) ao oídio (Sphaerotheca macularis f.sp. fragariae), em casa de vegetação.

\begin{tabular}{lcc}
\hline Cultivar & ID & Reação de resistência \\
\hline Santa Clara & $1,52 \mathrm{a}$ & Suscetível \\
Vila Nova & $1,41 \mathrm{a}$ & Suscetível \\
Bürkley & $1,27 \mathrm{a}$ & Suscetível \\
Dover & $1,03 \mathrm{~b}$ & Moderadamente suscetível \\
Campinas & $0,54 \mathrm{c}$ & Moderadamente resistente \\
Sweet Charlie & $0,42 \mathrm{c}$ & Moderadamente resistente \\
Oso Grande & $0,42 \mathrm{c}$ & Moderadamente resistente \\
Aromas & $0,38 \mathrm{c}$ & Moderadamente resistente \\
Camarosa & $0,38 \mathrm{c}$ & Moderadamente resistente \\
Milsei-Tudla & $0,25 \mathrm{~d}$ & Resistente \\
\hline Média & 0,76 & \\
CV $(\%)$ & 12,8 & \\
\hline
\end{tabular}

Médias seguidas de mesma letra minúscula não diferem entre si, pelo teste de Duncan, a $5 \%$ de probabilidade. $\mathrm{Na}$ análise estatística, os valores foram transformados em $\log (\mathrm{x}+1)$. Os dados de ID apresentados são originais.
As cultivares de morangueiro apresentaram alta variabilidade quanto à reação ao oídio (Tabela 1). As cultivares Santa Clara (ID=1,52), Vila Nova $(1,41)$ e Bürkley $(1,27)$ mostraram-se altamente suscetíveis. Estas cultivares são bastante utilizadas no sul do Rio Grande do Sul, apresentando frutos com elevada acidez e coloração acentuada, destinados à indústria. Em sua totalidade, não são cultivadas em ambiente protegido, o que minimiza a ocorrência do oídio. A cultivar Dover $(1,03)$ mostrou-se suscetível ao oídio, sendo uma cultivar bastante antiga, lançada em 1980, na Flórida (Howard \& Albregts, 1980), estando em fase gradual de substituição no Brasil. Os IDs das cultivares Campinas $(0,54)$, Sweet Charlie $(0,42)$, Oso Grande $(0,42)$, Aromas $(0,38)$ e Camarosa $(0,38)$ apresentaram valores inferiores a 1 , o que significa que menos de $25 \%$ da área foliar estava coberta com estruturas do fungo. Estas cultivares, que mostraram maior reação ao oídio do que as cultivares Bürkley, Dover, Santa Clara e Vila Nova, encontram-se entre as mais cultivadas em estufa e/ou túnel no País, sendo recomendadas para o mercado de frutas in natura. A cultivar Milsei-Tudla apresentou menor índice médio de doença $(0,25)$, podendo ser considerada a mais resistente entre as cultivares testadas. Conseqüentemente, também vem sendo recomendada para o cultivo em ambiente protegido. Nas cultivares estudadas, não se verificou reação de imunidade ao oídio.

TABELA 2 - Efeito da época de avaliação no desenvolvimento de oídio (Sphaerotheca macularis f.sp. fragariae) em matrizes de morangueiro (Fragaria $\mathrm{x}$ ananassa Duch.) cultivadas em casa de vegetação.

\begin{tabular}{lc}
\hline Época de avaliação após o transplantio & $\begin{array}{c}\text { Índice médio de doença } \\
\text { (ID) }\end{array}$ \\
\hline $8^{\mathrm{a}}$ semana & $1,00 \mathrm{a}$ \\
$10^{\mathrm{a}}$ semana & $0,76 \mathrm{~b}$ \\
$12^{\mathrm{a}}$ semana & $0,53 \mathrm{c}$ \\
\hline Média & 0,76 \\
$\mathrm{CV}(\%)$ & 18,1 \\
\hline
\end{tabular}

Médias seguidas de mesma letra minúscula não diferem entre si, pelo teste de Duncan, a $5 \%$ de probabilidade. $\mathrm{Na}$ análise estatística, os valores foram transformados em $\log (\mathrm{x}+1)$. Os dados de ID apresentados são originais.

No presente trabalho, pela primeira vez, as principais cultivares comerciais foram comparadas quanto ao nível de resistência ao oídio, complementando resultados descritos por outros autores em comparações realizadas com outras cultivares. Na Califórnia, a cultivar Camarosa foi descrita como menos resistente do que a 'Aromas', sendo esta última considerada relativamente resistente (Shasta Nursery, 2004). Xiao et al. (2001) consideraram a 'Camarosa' como suscetível sob condições de cultivo em ambiente protegido, porém não realizaram comparações com outras cultivares. Ainda sobre esse tema, Nelson et al. (1996) classificaram a 'Sweet Charlie' como mais resistente do que a 'Camarosa', e a 'Oso Grande' como moderadamente resistente.

Nas cultivares e condições estudadas, houve efeito da época de avaliação na severidade do oídio (Tabela 1). O índice médio de doença foi de 1,$00 ; 0,76$ e 0,53 , respectivamente, na $8^{\mathrm{a}}, 10^{\mathrm{a}}$ e $12^{\mathrm{a}}$ semana após o transplantio das matrizes nas bandejas em casa de vegetação. Desta forma, houve significativa redução dos sintomas da doença durante as avaliações, o que pode ser explicado pelas condições climáticas locais tornarem-se menos favoráveis com a proximidade do verão. Não se conseguiu manter a temperatura adequada para o desenvolvimento da doença na casa de vegetação onde foi realizado o experimento, pois o sistema de refrigeração não foi suficiente, tendo chegado a $30^{\circ} \mathrm{C}$ nos dias mais quentes. Segundo Mass (1998), Xiao et al. (2001) e Fortes \& Couto (2003), alta incidência luminosa, dias mais longos e temperaturas superiores a $27^{\circ} \mathrm{C}$ são desfavoráveis à disseminação e à colonização dos tecidos das plantas de morangueiro.

Não se verificou interação significativa a $5 \%$ de probabilidade entre as variáveis época de avaliação e cultivar. Portanto, as cultivares apresentaram a mesma reação de resistência ao oídio em todas as épocas 
de avaliação.

Os resultados obtidos são importantes na definição das cultivares e no tipo de manejo a ser adotado no controle do oídio na cultura do morangueiro. As cultivares com maior nível de resistência, como a Milsei-Tudla, Camarosa, Aromas, Oso Grande, Sweet Charlie e Campinas devem ser as preferidas pelos agricultores, notadamente para a produção em ambiente protegido. No caso das cultivares altamente suscetíveis, como a Santa Clara, Vila Nova e Bürkley, maior atenção deve ser dada à adoção de práticas culturais e ao uso de fungicidas visando à prevenção e ao controle da doença, pois a produtividade e a qualidade dos frutos são função direta da área foliar capaz de realizar a fotossíntese (Ronque, 1998). Segundo Nelson et al. (1996), os programas de melhoramento atuais vêm buscando aumentar o nível de resistência das cultivares ao oídio, caráter este que apresenta herança aditiva, com o objetivo de reduzir o uso de defensivos químicos na cultura. Por isso, as cultivares lançadas mais recentemente são justamente as de maior nível de resistência.

O método natural de inoculação utilizado, distribuindo-se bandejas com plantas infectadas no interior do ambiente protegido, mostrou-se eficiente, pois todas as cultivares estudadas apresentaram desenvolvimento do fungo, inclusive as da cv. Aromas, considerada relativamente resistente (Shasta Nursery, 2004). A movimentação de ar no interior da casa de vegetação, proporcionada pelo sistema de controle da temperatura, certamente potencializou a distribuição dos esporos do fungo, pois o vento é relatado como importante meio de disseminação da doença à curta distância (Fortes \& Couto, 2003).

\section{CONCLUSÕES}

1. As cultivares de morangueiro testadas apresentam diferentes reações de resistência ao oídio.

2. A reação de cultivares de morangueiro quanto à resistência apresenta a seguinte classificação: 'Milsei-Tudla' resistente; 'Camarosa', 'Aromas', 'Oso Grande', 'Sweet Charlie' e 'Campinas' moderadamente resistente; 'Dover' moderadamente suscetível; e 'Vila Nova', 'Santa Clara' e 'Bürkley' suscetíveis.

\section{REFERÊNCIAS}

FORTES, J.F.; COUTO, M.E. Doenças fúngicas e bacterianas. In: FORTES, J. F.; OSÓRIO, V.A. (Ed.). Morango: fitossanidade. Brasília: Embrapa Clima Temperado/Embrapa Informação Tecnológicas, 2003. p.11-18.

HOWARD, C.M.; ALBREGTS, E.E. 'Dover' strawberry. HortScience, Alexandria, v.15, n.4, p.540, 1980.

LEGARD, D.E.; XIAO, C.L.; MERTELY, J.C. Evaluation of fungicides to control powdery mildew and Botrytis fruit rot of strawberry. Fungicide Nematicide Tests, Ithaca, v.55, p.130, 1999.

MASS, J.L. Compendium of strawberry diseases. $2^{\text {nd }}$ ed. St. Paul: APS Press, 1998. 98p.

MILLER, T.C.; GUBLER, W.D.; GENE, S.; RIZZO, D.M. Effects of temperature and water vapor pressure on conidial germination and lesion expansion of Sphaerotheca macularis f.sp. fragariae. Plant Disease, St. Paul, v.87, p.484-492, 2003.

NELSON, M.D.; GUBLER, W.D.; SHAW, D.V. Relative resistance of 47 strawberry cultivars to powdery mildew in California greenhouse and field environments. Plant Disease, St. Paul, v.80, p.326-328, 1996.

OLIVEIRA JÚNIOR, M.E.; MANICA, I. Principais países produtores de frutas no ano de 2002. Jornal da Fruta, Lages, v.11, n.127, p.14, 2003.

OSÓRIO, V.A.; FORTES, J.F. Introdução. In: FORTES, J. F.; OSÓRIO, V.A. (Ed.). Morango: fitossanidade. Brasília: Embrapa Clima Temperado/Embrapa Informação Tecnológica, 2003. p.9-10.

RESENDE, L.M.A.; MASCARENHAS, M.H.T.; PAIVA, B.M. Panorama da produção e comercialização de morango. Informe Agropecuário, Belo Horizonte, v.20, n.198, p.5-19, 1999.

RONQUE, E.R.V. A cultura do morangueiro. Curitiba: Emater, 1998. 206p.

SHASTA NURSERY. Strawberry variety descriptions. Disponível em: $<$ http://www.rootstock.com/variety.html>. Acesso em: 30 set. 2004.

STAUDT, G. Taxonomic studies in the genus Fragaria; typification of the Fragaria species known at the time of Linnaeus. Canadian Journal of Botany, Ottawa, v.40, p.869-886, 1962.

XIAO, C.L.; CHANDLER, C.K.; PRICE, J.F.; DUVAL, J.R.; MERTELY, J.C.; LEGARD, D.E. Comparison of epidemics of Botrytis fruit rot and powdery mildew of strawberry in large plastic tunnel and field production system. Plant Disease, St. Paul, v.85, p.901-909, 2001. 